Physics International 1 (2): 83-89, 2010

ISSN 1948-9803

(C) 2010 Science Publications

\title{
The Influence of Information Sharing on Supply Chain Management
}

\author{
Chiang Wang \\ Institute of Marketing and Logistics, Southern Taiwan University of Technology, \\ No. 1, Nan-Tai Street, Yongkang Dist., Tainan City 710, Taiwan R.O.C
}

\begin{abstract}
Problem statement: Implementing information sharing and coordination can enhance the performance of supply chain management, such as a short response time, minimum cost, low inventory and joint production and transportation. Approach: Through information sharing among all supply chain members, stable long-term relationships can be established and maintained. Results: This study uses a quantitative cost model to identify the interaction among the supply chain members and to analyze the benefits of implementing information sharing. Conclusion: Through the joint procurement, production and transportation that is made possible under information sharing, the total cost of supply chain collaboration can be optimized for better supply chain management. Moreover, a successful supply chain management system with effective strategies can also be facilitated.
\end{abstract}

Key words: Information sharing, supply chain collaboration, Early Order Commitment (EOC), implemented efficiently, implementing information, joint production, long-term relationships, collaborative planning, collaboration emphasizes, inventory risks

\section{INTRODUCTION}

Supply chain management can use information sharing and coordination to facilitate logistical efficiency and thus achieve the goals of a short response time, minimum cost, low inventory and joint production and transportation. Sahin and Robinson (2005) also considered that the more complete the information sharing is, the more the cost can be reduced without inventory risks through joint planning by suppliers and manufacturers. Moreover, by following such policies collaborative planning and execution, such as the coordination of purchasing, manufacturing and product delivery, can be implemented efficiently among supply chain partners.

Information sharing is often considered as a generic cure for the bullwhip effect and one that can improve overall supply chain performance (Huang and Gangopadhyay, 2004). Through information sharing among all the partners in a supply chain, the upstream material suppliers are be able to modify their production strategies from make-to-order to make-to-stock after obtaining figures on future demand from the downstream retailers. Additionally, the suppliers' batching delivery strategies can also be formulated so that the delivery date can reduce the total cost for the downstream retailers, since it can mitigate the bullwhip effect and achieve better performance (Sahin and Robinson, 2005).
The cost is the most important index when a downstream producer chooses its upstream suppliers (Li and Kouvelis, 1999). This study aims to create a cost model to confirm how the information sharing status between members in the supply chain would influence the costs between material suppliers, producers and delivery centers. Moreover, through the combined processes of purchasing, production and product delivery of all the partners involved in the operation of a supply chain, the total cost of the chain can be optimized for better supply chain management when there is a stronger willingness to share information and more stable partner relationships.

Literature review: Information sharing can reduce inventory level in the operation of a supply chain. Specifically, when the bullwhip effect emerges from asymmetric information in a supply chain, locally optimal decisions are made by each individual firm. When the partners in a supply chain are willing to share their customer demand forecasts, the bullwhip effect can be reduced efficiently because the information demands are treated in an integrated fashion (Chen et al., 2000). Sahin and Robinson (2005) found that the more integrated information sharing is, the stronger the ability of joint planning between suppliers, manufacturers, logistics and retailers can be. A series of supply chain planning operations, such as production planning,

(C) 2010 Chiang Wang. This open access article is distributed under a Creative Commons Attribution (CC-BY) 3.0 license which permits unrestricted use, distribution, and reproduction in any medium, provided the original work is properly credited. DOI: 10.3844/pisp.2010.83.89 
inventory planning and shipment planning, should thus be initiated and communication and collaboration between business partners should also be encouraged to enhance the potential benefits of information sharing. In addition, there are many scholars have focused on the discussion the information sharing, and their works can be found in the literature (Shareha et al., 2009; Barnes and Rai, 2010; Elmetwaly, 2011; Olugu and Wong, 2009; Takemura, 2010; Wagner, 2010).

Huang and Gangopadhyay (2004) defined three degrees of information sharing as follows: no information sharing, partial information sharing and full information sharing. Compared with full information sharing, which implies that all partners are integrated together, partial information sharing, which is examined using a 50\% information sharing model, means that all partners are connected randomly.

In the traditional make-to-stock supply chain system, Fransoo and Wouters (2000) theorized that the existence of the bullwhip effect increases the cost of the system. Chen et al. (2000) utilized a two-stage supply chain model to analyze the causal factors of the bullwhip effect by using a quantitative model to investigate its influence on the efficiency of a make-tostock supply chain and to monitor the inventory strategies and the customer demand forecasts between a single manufacturer and single retailer. Their findings revealed that only when each member in the supply chain shares information could the negative impact of the bullwhip effect be effectively reduced, although not completely eliminated. Zhao (2002) also quantified the impact of the traditional make-to-stock system with and without information sharing on the manufacturer and found that the former can provide significant cost savings. Although the system in Zhao (2002) was designed to measure the benefits of information sharing with a quantitative model, the model was not able to work properly under the uncertainty of the product demand in a make-to-stock supply chain, which is based on the demand forecast. Accordingly, Sahin and Robinson (2005) suggested a make-to-order system based on the actual demand, put information sharing into three different categories according to the MRP information on tangible orders and developed a linear model to estimate the influence of the delivery quantity and schedule arrangement of the suppliers on the total cost of supply chain under the three different information sharing statuses. Their results showed that the more information is shared, the more demand variability, logistics costs and infrastructure cost are reduced. Through integrated material delivery, the suppliers are able to reduce the delivery cost and still comply with the manufacturers' demands. Therefore, this study aims to find ways to combine the make-toorder and make-to-stock supply chain systems.

Model construction: Tomas and Griffin (1996) concluded that the members involved in a supply chain include material suppliers, manufacturers, distribution centers, retailers and customers. When joint procurement, production and transportation are successfully implemented among these members through information sharing, the optimization of the supply chain can be achieved (Sahin and Robinson, 2005).

Under information sharing, the downstream retailer can provide an Early Order Commitment (EOC) based on the real customer demand forecast for any given planning period. The early order commitment is released by a downstream company that commits to purchase a fixed-order quantity at a set delivery time for a certain product item from an upstream supplier before the real demand has occurred (Zhao et al., 2002). Zhao et al. (2002) argued that the practice of early order commitment can generate significant savings in the supply chain within a range of order commitment periods. When the early order commitment of a retailer is delivered to the upstream distribution center, the latter can develop its new early order commitment according to the transportation plan and deliver it to the upstream manufacturer. After receiving the early order commitment from the distribution center, the manufacturer can proceed with the procurement, production and transportation plans. The interrelation of procurement, production and transportation plans among retailer, distribution center and manufacturer is both clear and significant in such a system. The successful joint procurement, production and transportation strategies are simultaneously implemented across the participating companies to achieve global optimization through the early order commitment, which is the communication and collaboration platform among supply chain partners under information sharing. In contrast, early order commitment does not exist in a supply chain partnership without information sharing, wherein the demand of a downstream company is only delivered to the upstream company on a lot by lot basis. Accordingly, joint procurement, production and transportation cannot be simultaneously implemented among the participating companies. Under such conditions, every company only individually attains its optimal procurement, production and transportation strategies and operations and global optimization for the whole supply chain is unlikely to be achieved.

In order to determine the differences in supply chain performance with and without information sharing, a cost model is developed in this study. 
Phy. Intl. 1 (2): 83-89, 2010

Through a consideration of cost differences we can figure out the optimal collaboration processes of supply chain partnership and derive some managerial insights for improved information sharing.

In order to identify the interaction among supply chain members and to analyze the benefits of information sharing, a three-tier (retailer, distributor and manufacturer) supply chain structure is adopted here. For any given period, the retailer first starts developing the early order commitment from the real demand forecast. In addition, the forecasted demand for the $j^{\text {th }}$ day, $u_{j}{ }_{j}$, is obtained in the early order commitment. If information sharing is implemented, the retailer can deliver the early order commitment to the upstream distribution center so that the center can arrange the transportation date and transportation volume. Since the early order commitment just needs to be processed one time, the ordering cost of the retailer, $\mathrm{O}^{\mathrm{R}}$, is:

$$
\mathrm{O}^{\mathrm{R}}=\mathrm{O}^{\mathrm{R}}
$$

where, $o^{\mathrm{R}}$ is the ordering cost of the retailer per order.

Assume that the $A_{j}^{D C}$ is the quantity replenished from the distribution center on the $j^{\text {th }}$ day and that $S_{0}^{R}$ is the initial inventory kept in the retailer, the inventory kept in the retailer on the $\mathrm{j}^{\text {th }}$ day, $\mathrm{S}_{\mathrm{j}}^{\mathrm{R}}$, is:

$S_{j}^{R}=S_{j-1}^{R}+A_{j}^{D C}-u_{j}^{R}$

For each $\mathrm{j}$.

And the total inventory holding cost of the retailer, $\mathrm{H}^{\mathrm{R}}$, is:

$$
H^{R}=\sum_{j} h^{R} \times S_{j}^{R}
$$

For all $\mathrm{j}$.

where, ${ }^{R}$ is the unit inventory holding cost of the retailer.

When the products have been delivered to the retailer from the distribution center, the inspection cost of the retailer, $P^{R}$, is:

$$
P^{R}=\sum_{j} p_{f}^{R} \times Y_{j}^{R}+p_{v}^{R} \times A_{j}^{D C}
$$

For all $\mathrm{j}$
Where:

$p_{f}{ }^{R}=$ The fixed inspection cost of the retailer

$p_{v}^{R}=$ The unit variable inspection cost of the retailer

$$
Y_{j}^{R}= \begin{cases}1 & \text { when } A_{j}^{D C}>0 \\ 0 & \text { when } A_{j}^{D C}=0\end{cases}
$$

Accordingly, the total cost of the retailer, $\mathrm{TC}^{\mathrm{R}}$, is:

$\mathrm{TC}^{\mathrm{R}}=\mathrm{O}^{\mathrm{R}}+\mathrm{H}^{\mathrm{R}}+\mathrm{P}^{\mathrm{R}}$

In addition, the information revealed in the early order commitment will be transformed to the transportation demand of the distribution center when the distribution center receives the early order commitment that has been delivered by the retailer. Assume that the transportation demand of the distribution center on the $i^{\text {th }}$ day is $u_{i}{ }^{D C}$. After considering the joint transportation, the $\mathrm{u}_{\mathrm{i}}{ }^{\mathrm{DC}}$ may be merged with numerous transportation batches on the $j^{\text {th }}$ day, $A_{j}$ and then delivered to the retailer. The relationship is:

$$
A_{j}^{D C}=\sum_{i} u_{i}^{D C} \times x_{i j}^{D C}
$$

For each j:

$$
\text { St. } \sum_{\mathrm{j}} \mathrm{x}_{\mathrm{ij}}^{\mathrm{DC}}=1
$$

Where:

$x_{i j}^{D C}= \begin{cases}1 & \text { when the } u_{i}{ }^{D C} \text { is merged to deliver on the } j^{\text {th }} \text { day } \\ 0 & \text { when the } u_{i} \text { id } \text { is not merged to deliver on the } j^{\text {th }} \text { day }\end{cases}$

The total transportation cost of the distribution center, $\mathrm{T}^{\mathrm{DC}}$, is:

$$
\mathrm{T}^{\mathrm{DC}}=\sum_{\mathrm{j}} \mathrm{t}_{\mathrm{f}}^{\mathrm{DC}} \times \mathrm{X}_{\mathrm{j}}^{\mathrm{DC}}+\mathrm{t}_{\mathrm{v}}^{\mathrm{DC}} \times \mathrm{A}_{\mathrm{j}}^{\mathrm{DC}}
$$

For all $\mathrm{j}$.

Where: 
Phy. Intl. 1 (2): 83-89, 2010

$\mathfrak{t}_{f}^{D C}=$ The fixed transportation cost of the distribution center

$\mathrm{t}_{\mathrm{v}}^{\mathrm{DC}}=$ The unit variable transportation cost of the distribution center

$$
X_{j}^{D C}= \begin{cases}1 & \text { when } A_{j}^{D C}>0 \\ 0 & \text { when } A_{j}^{D C}=0\end{cases}
$$

The development of the early order commitment of the distribution center is similar to that of the retailer. The early order commitment of the distribution center can be formed by $\mathrm{A}_{j}^{\mathrm{DC}}$; furthermore, it is also delivered to the upstream manufacturer under information sharing. Since the early order commitment has been delivered completely to the upstream manufacturer, the ordering cost of the distribution center, $\mathrm{O}^{\mathrm{DC}}$, is:

$$
\mathrm{O}^{\mathrm{DC}}=\mathrm{O}^{\mathrm{DC}}
$$

where, $\mathrm{O}^{\mathrm{DC}}$ is the ordering cost of the distribution center per order.

Assume that $B_{j}{ }_{j}$ is the quantity replenished from the manufacturer on the $\mathrm{j}^{\text {th }}$ day and the $\mathrm{S}_{0}^{\mathrm{DC}}$ is the initial inventory kept in the distribution center, the inventory kept in the distribution center on the $j^{\text {th }}$ day, $S_{j}$, is:

$$
S_{j}^{D C}=S_{j-1}^{D C}+B_{j}^{M}-A_{j}^{D C}
$$

For each $\mathrm{j}$,

And the total inventory holding cost of the distribution center, $\mathrm{H}^{\mathrm{DC}}$, is:

$$
H^{D C}=\sum_{j} h^{D C} \times S_{j}^{D C}
$$

For all $\mathrm{j}$.

where, $h^{D C}$ is the unit inventory holding cost of the distribution center.

When the products have been delivered to the distribution center from the manufacturer, the inspection cost of the distribution center, $\mathrm{P}^{\mathrm{DC}}$, is:

$$
P^{D C}=\sum_{j} p_{f}^{D C} \times Y_{j}^{D C}+p_{v}^{D C} \times B_{j}^{M}
$$

For all $\mathrm{j}$.

Where: $\begin{aligned} \mathrm{p}_{\mathrm{f}}^{\mathrm{DC}}= & \text { The fixed inspection cost of the distribution } \\ & \text { center }\end{aligned}$ $\mathrm{p}_{\mathrm{v}}^{\mathrm{DC}}=$ The unit variable inspection cost of the distribution center

$$
Y_{j}^{D C}= \begin{cases}1 & \text { when } B_{j}^{M}>0 \\ 0 & \text { when } B_{j}^{M}=0\end{cases}
$$

Thus the total cost of the distribution center, $\mathrm{TC}^{\mathrm{DC}}$, is:

$$
\mathrm{TC}^{\mathrm{DC}}=\mathrm{T}^{\mathrm{DC}}+\mathrm{O}^{\mathrm{DC}}+\mathrm{H}^{\mathrm{DC}}+\mathrm{P}^{\mathrm{DC}}
$$

Finally, the early order commitment of the distribution center will be further transformed to the transportation and production demand of the manufacturer. Assume that the transportation demand of the manufacturer on the $i^{\text {th }}$ day is $u_{i}{ }^{M}$ After considering the joint transportation, $u_{i}{ }_{i}$ may be merged with numerous transportation batches on the $j^{\text {th }}$ day, $B_{j}{ }^{M}$ and then delivered to the distribution center. The relationship is:

$$
B_{j}^{M}=\sum_{i} u_{i}^{M} \times x_{i j}^{M}
$$

For each $\mathrm{j}$.

$$
\text { St. } \sum_{\mathrm{j}} \mathrm{x}_{\mathrm{ij}}^{\mathrm{M}}=1
$$

Where:

$x_{i j}^{M}= \begin{cases}1 & \text { when the } u_{i}{ }^{M} \text { is merged to deliver on the } j^{\text {th }} \text { day } \\ 0 & \text { when the } u_{i}{ }^{M} \text { is not merged to deliver on the } j^{\text {th }} \text { day }\end{cases}$

The total transportation cost of the manufacturer, $\mathrm{T}^{\mathrm{M}}$, is:

$$
T^{M}=\sum_{j} t_{f}^{M} \times X_{j}^{M}+t_{v}^{M} \times B_{j}^{M}
$$

For all $\mathrm{j}$

Where:

$\mathrm{t}_{\mathrm{f}}^{\mathrm{M}}=$ The fixed transportation cost of the manufacturer

$\mathrm{t}_{\mathrm{v}}^{\mathrm{M}}=$ The unit variable transportation cost of the manufacturer 
Phy. Intl. 1 (2): 83-89, 2010

$$
X_{j}^{M}= \begin{cases}1 & \text { when } B_{j}^{M}>0 \\ 0 & \text { when } B_{j}^{M}=0\end{cases}
$$

Since the manufacturer can arrange the production plan in accordance with $\mathrm{u}_{\mathrm{i}}{ }^{\mathrm{M}}$, the production batch, $\mathrm{C}_{\mathrm{j}}^{\mathrm{M}}$, that the manufacturer produces on the $\mathrm{j}^{\text {th }}$ day, can be obtained through the joint production of $\mathrm{u}_{\mathrm{i}}{ }^{\mathrm{M}}$ :

$$
\mathrm{C}_{\mathrm{j}}^{\mathrm{M}}=\sum_{\mathrm{i}} \mathrm{u}_{\mathrm{i}}^{\mathrm{M}} \times \mathrm{y}_{\mathrm{ij}}^{\mathrm{M}}
$$

For each $\mathrm{j}$.

St. $\sum_{\mathrm{j}} \mathrm{y}_{\mathrm{ij}}^{\mathrm{M}}=1$

Where:

$y_{i j}^{M}=\left\{\begin{array}{l}1 \text { when the } u_{i}^{M} \text { is merged to produce on the } j^{\text {th }} \text { day } \\ 0 \quad \text { when the } u_{i}{ }^{M} \text { is not merged to produce on the } j^{\text {th }} \text { day }\end{array}\right.$

Thus, the production cost of the manufacturer, $\mathrm{R}^{\mathrm{M}}$, is:

$$
R^{M}=\sum r_{f}^{M} \times Y_{j}^{M}+r_{v}^{M} \times C_{j}^{M}
$$

For all $\mathrm{j}$.

Where:

$r_{f}^{M}=$ The fixed production cost of the manufacturer

$r_{v}^{M}=$ The unit variable production cost of the manufacturer

$$
Y_{j}^{M}= \begin{cases}1 & \text { when } C_{j}^{M}>0 \\ 0 & \text { when } C_{j}^{M}=0\end{cases}
$$

Assume that $\mathrm{S}_{0}^{\mathrm{Ml}}$ is the initial product inventory being kept by the manufacturer, the product inventory kept by the manufacturer on the $\mathrm{j}^{\text {th }}$ day, $\mathrm{S}_{\mathrm{j}}^{\mathrm{Ml}}$, is:

$$
S_{j}^{M 1}=S_{j-1}^{M 1}+C_{j}^{M}-B_{j}^{M}
$$

For each $\mathrm{j}$,

And the total product inventory holding cost of the manufacturer, $\mathrm{H}^{\mathrm{Ml}}$, is:

$$
\mathrm{H}^{\mathrm{M} 1}=\sum_{\mathrm{j}} \mathrm{h}^{\mathrm{M} 1} \times \mathrm{S}_{\mathrm{j}}^{\mathrm{M} 1}
$$

For all $\mathrm{j}$

where, $h^{\mathrm{M} 1}$ is the unit product inventory holding cost of the manufacturer.

Through the examination of the Bill Of Material (BOM) of this product, the material requirements used in the production can be obtained. Assume that the quantity of the major component required to make one unit of product is $\mathrm{k}$ ( $\mathrm{k}$ is constant), the requirement of this component on the $\mathrm{j}^{\text {th }}$ day, $\mathrm{d}_{\mathrm{j}}{ }^{\mathrm{M}}$, is:

$$
\mathrm{d}_{\mathrm{j}}^{\mathrm{M}}=\mathrm{k} \times \mathrm{C}_{\mathrm{j}}^{\mathrm{M}}
$$

The component requirements will also be transformed into the material procurement demand of the manufacturer. If the lead time of material procurement is not considered, the material volume that the manufacturer needs on the $i^{\text {th }}$ day, $v_{i}{ }_{i}$, is equal to $d_{j}^{M}$. In order to achieve a lower cost, the manufacturer can develop its material procurement plan according to the material ordering cost, material inspection cost and material holding cost. If the joint procurement is implemented, the $\mathrm{v}_{\mathrm{i}}^{\mathrm{M}}$ may be merged with numerous procurement batches, $D_{j}^{M}$. Consequently, this phenomenon will occur if the supplier is asked to deliver on the $\mathrm{j}^{\text {th }}$ day:

$$
D_{j}^{M}=\sum_{i} v_{i}^{M} \times w_{i j}^{M}
$$

for each $\mathrm{j}$ :

$$
\text { St. } \sum_{\mathrm{j}} \mathrm{w}_{\mathrm{ij}}{ }^{\mathrm{M}}=1
$$

Where:

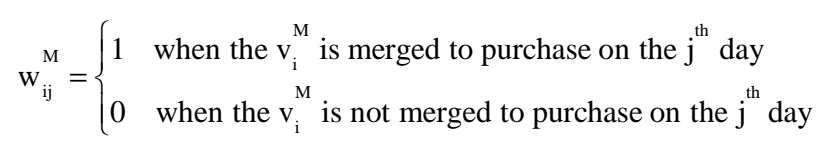

The material ordering cost of the manufacturer, $\mathrm{O}^{\mathrm{M}}$ and the material inspection cost, $\mathrm{P}^{\mathrm{M}}$, are:

$$
\mathrm{O}^{\mathrm{M}}=\sum_{\mathrm{j}} \mathrm{o}^{\mathrm{M}} \times \mathrm{W}_{\mathrm{j}}^{\mathrm{M}}
$$


Phy. Intl. 1 (2): 83-89, 2010

For all j:

$$
\mathrm{P}^{\mathrm{M}}=\sum_{\mathrm{j}} \mathrm{p}_{\mathrm{f}}^{\mathrm{M}} \times \mathrm{W}_{\mathrm{j}}^{\mathrm{M}}+\mathrm{p}_{\mathrm{v}}^{\mathrm{M}} \times \mathrm{D}_{\mathrm{j}}^{\mathrm{M}}
$$

Where:

$$
\begin{aligned}
\mathrm{o}^{\mathrm{M}}= & \text { The material ordering cost of the manufacturer } \\
& \text { per order } \\
\mathrm{p}_{\mathrm{f}}^{\mathrm{M}}= & \text { The fixed material inspection cost of the } \\
& \text { manufacturer } \\
\mathrm{p}_{\mathrm{v}}^{\mathrm{M}}= & \text { The variable material inspection cost of the } \\
& \text { manufacturer }
\end{aligned}
$$

$$
\mathrm{W}_{\mathrm{j}}^{\mathrm{M}}= \begin{cases}1 & \text { when } \mathrm{D}_{\mathrm{j}}^{\mathrm{M}}>0 \\ 0 & \text { when } \mathrm{D}_{\mathrm{j}}^{\mathrm{M}}=0\end{cases}
$$

Since the supplier is not considered in this model, the manufacturer can decide on the material procurement plan that includes the date and volume of procurement by itself, reducing the material procurement cost and synchronizing all the related operations. Assume that $\mathrm{S}_{0}^{\mathrm{M} 2}$ is the initial material inventory kept by the manufacturer, then the material inventory kept in the manufacturer on the $\mathrm{j}^{\text {th }}$ day, $\mathrm{S}_{\mathrm{j}}^{\mathrm{M} 2}$, is:

$S_{j}^{M 2}=S_{j-1}^{M 2}+D_{j}^{M}-d_{j}^{M}$

For each $\mathrm{j}$,

And the total material inventory holding cost of the manufacturer, $\mathrm{H}^{\mathrm{M} 2}$, is:

$$
\mathrm{H}^{\mathrm{M} 2}=\sum_{\mathrm{i}} \mathrm{h}^{\mathrm{M} 2} \times \mathrm{S}_{\mathrm{j}}^{\mathrm{M} 2}
$$

For all $\mathrm{j}$.

Where:

$\mathrm{h}^{\mathrm{M} 2}=$ The unit material inventory holding cost of the manufacturer.

Thus the total cost of the manufacturer, $\mathrm{TC}^{\mathrm{M}}$, is:

$$
\mathrm{TC}^{\mathrm{M}}=\mathrm{T}^{\mathrm{M}}+\mathrm{R}^{\mathrm{M}}+\mathrm{H}^{\mathrm{M} 1}+\mathrm{O}^{\mathrm{M}}+\mathrm{P}^{\mathrm{M}}+\mathrm{H}^{\mathrm{M} 2}
$$

The main objective of this study is to minimize the total cost of the supply chain, TC, through the implementation of joint procurement, production and transportation, which are embodied in the solutions of all decision-making variables involved in the model.
Under information sharing, all members involved in the supply chain should make their procurement, production and transportation decisions simultaneously to achieve global optimization, since these decisions are interrelated. If the operations and strategies of all supply chain partners are synchronized, the performance will be enhanced successfully.

On the other hand, the procurement, production and transportation among these supply chain partners will be implemented on a lot by lot basis if the early order commitment is not developed without information sharing. Although the proposed cost model is still applicable for any given planning period, each decision variable embedded in this model is equal to 0 . In this situation the members in the supply chain can only arrange the procurement, production and transportation plans independently by themselves to achieve local optimization. Furthermore, while many studies have developed theories and models to demonstrate the advantage of implementing information sharing, the interrelations among all the supply chain partners have rarely been discussed from the viewpoint of operating cost. Consequently, this study aims to explore the interrelation among all the supply chain partners through a quantitative model and to investigate how their coordination can be synchronized through the implementation of joint procurement, production and transportation.

\section{CONCLUSION}

Supply chain collaboration emphasizes the stable, long-term relationships among members which can be established and maintained by implementing information sharing. The development of a supply chain strategy is of vital importance to achieving the optimization of supply chain coordination. In this study, a quantitative cost model is used to examine the interaction among supply chain members and to analyze the benefits of implementing information sharing. The results clearly show that the total cost can be reduced effectively through joint procurement, production and transportation when information sharing is implemented in the supply chain by a process of early order commitment. Moreover, the decrease in total cost is more substantial under information sharing when the fixed cost is higher.

\section{ACKNOWLEDGEMENT}

This study is partially supported by the National Science Council of Taiwan under grant NSC96-2416H-218-007. 


\section{REFERENCES}

Barnes, C.N. and S.N. Rai, 2010. Modeling heterogeneity in phase ii clinical trials. Am. J. Biostat., 1: 9-16. DOI: 10.3844/amjbsp.2010.9.16

Chen, F., Z. Drezner, J.K. Ryan and D. Simchi-Levi, 2000. Quantifying the bullwhip effect in a simple supply chain: The impact of forecasting, lead times, and information. Manage. Sci., 46: 436-443. DOI: $10.1287 / \mathrm{mnsc} .46 .3 .436 .12069$

Elmetwaly, H.M.M., 2011. Design and implementation of medical information systems for managing and following up work flaw in hospitals and clinics. J. Comput. Sci., 7: 27-31. DOI: 10.3844/jcssp.2011.27.31

Fransoo, J.C. and M.J.F. Wouters, 2000. Measuring the bullwhip effect in the supply chain. Supply Chain Manage., 5 : $78-89 . \quad$ DOI: $10.1108 / 13598540010319993$

Huang, Z. and A. Gangopadhyay, 2004. A simulation study of supply chain management to measure the impact of information sharing. Infom. Resour. Manage. J., 17: 20-31. DOI: 10.4018/irmj.2004070102

Li, C.L. and P. Kouvelis, 1999. Flexible and risksharing supply contracts under price uncertainty. Manage. Sci., 45: 1378-1398. DOI: 10.1287/mnsc. 45.10 .1378
Olugu, E.U. and K.Y. Wong, 2009. Supply chain performance evaluation: Trends and challenges. Am. J. Eng. Applied. Sci., 2: 202-211. DOI: 10.3844/ajeassp.2009.202.211

Sahin, F. and E.P. Robinson, 2005. Information sharing and coordination in make-to-order supply chains. J. Oper. Manage., 23: 579-598. DOI: 10.1016/j.jom.2004.08.007

Shareha, A.A.A., M. Rajeswari and D. Ramachandram, 2009. Multimodal integration (image and text) using ontology alignment. Am. J. Applied Sci., 6: 1217-1224. DOI: 10.3844/ajassp.2009.1217.1224

Takemura, T., 2010. A quantitative study on japanese workers' awareness to information security using the data collected by web-based survey. Am. J. Econ. Bus. Admin., 2: 20-26. DOI: 10.3844/ajebasp.2010.20.26

Tomas, D.J. and P.M. Griffin, 1996. Coordinated supply chain management. Eur. J. Oper. Res., 94: 1-15. DOI: 10.1016/0377-2217(96)00098-7

Wagner, M., 2010. Forecasting daily demand in cash supply chains. Am. J. Econ. Bus. Admin., 2: 377-383. DOI: 10.3844/ajebasp.2010.377.383

Zhao, X, J. Xie and J.C. Wei, 2002. The impact of forecast errors on early order commitment in a supply chain. Decision Sci., 33: 251-280. DOI: 10.1111/j.1540-5915.2002.tb01644.x 